\title{
Molecular and serologic characterization of rotavirus from children with acute gastroenteritis in northern Iran, Gorgan
}

\author{
Nazanin Lorestani ${ }^{1}$, Abdolvahhab Moradi ${ }^{2}$, Ali Teimoori ${ }^{3}$, Maha Masodi², Sayyad Khanizadeh ${ }^{4,5}$, Mina Hassanpour ${ }^{2}$,
} Naemeh Javid ${ }^{2}$, Abdollah Ardebili, ${ }^{1,2}$ Alijan Tabarraei ${ }^{2}$ and Hadi Razavi Nikoo ${ }^{1,2^{*}}$

\begin{abstract}
Background: The pattern and distribution of human rotavirus genotypes in young children in developing countries play an important role in epidemiological studies, as well as providing a strategy for the development of future rotavirus vaccine.

Methods: We evaluated stool samples from 349 children with acute gastroenteritis from Northern Iran (Gorgan city, Golestan province). Polyacrylamide Gel Electrophoresis (PAGE) and Latex Agglutination Test (LAT) were utilized to determine the prevalence of human rotavirus in fecal samples. Moreover semi-multiplex RT-PCR technique was carried out in order to determine the P and $\mathrm{G}$ genotypes of human rotavirus in rotavirus-positive samples.

Results: A total of 46 rotavirus-positive samples were $G$ and $P$ genotyped. Whereas 28 (60.8\%) fecal specimens contained only one rotavirus strain, 14 (30.4\%) were mixed rotavirus infections and 4 (8.8\%) was non-typeable. Overall, during the study, 57.82\% of strains identified as genotype G1, G2 (18.70\%), G3 (4.69\%), G4 (3.13\%), G8 (3.13\%), G9 (6.26\%) and non-typeable G (6.26\%). From all these mentioned rotavirus strains, 46 were characterized as P [8] (97.80\%) and P [4] (2.20\%).Our analysis of the $G$ and P genotyping of strains from all 46 rotavirus-infected children has revealed that $4 / 46(6.26 \%)$ of $G$ type strains were non-typeable. The predominant single $G / P$ combination was G1P [8] (57.82\%), followed by, G2P [8] (16.98\%), G2P [4] (1.72\%), G3P [8] (4.69\%), G4P [8] (3.13\%) G8P [8] (3.13\%), G9P [8] (6.26\%) and four cases of non-typeable G (6.26\%). Rotavirus was detected in 39 specimens (11.17\%) by PAGE and in 38 specimens (10.88\%) by LAT. Both tests were 100\% specific; however, the LAT was $82.61 \%$ sensitive compared to the PAGE, which was $84.78 \%$ sensitive.
\end{abstract}

Conclusions: The results suggest that to characterize rotavirus strains as well as design new effective vaccines for children with acute gastroenteritis, a large-scale study is needed in future.

Keywords: Rotavirus, Genotyping, Serotyping, Gastroenteritis, Iran

\section{Background}

Diarrhea disease is the eighth leading cause of annual death among all ages for more than 1.6 million deaths and the fifth leading cause of death among under 5 years old children worldwide [1]. According to the World Health Organization (WHO), gastroenteritis affects generally 3 to 5 million children each year, of which nearly

\footnotetext{
* Correspondence: hadirazavi96@gmail.com

'Laboratory Sciences Research Center, Golestan University of Medical Sciences, Gorgan, Iran

${ }^{2}$ Department of Microbiology, Faculty of Medicine, Golestan University of Medical Sciences, Gorgan, Iran

Full list of author information is available at the end of the article
}

$12 \%$ are children younger than 5 years in 2015, responsible for nearly 446,000 deaths $[1,2]$. The morbidity and mortality rate of gastroenteritis is increasing in developing countries. Acute gastroenteritis is one of the main public health problems caused by various well known pathogens, including: bacteria, protozoa and viral pathogens [3]. Recent studies have shown that enteric viruses, especially Rotavirus is the most important etiological agents for diarrhea mortality among children younger than 5 years with more than 128,000 deaths occur annually in the world $[1,4,5]$. The high percentage of rotavirus-related deaths $(>80 \%)$ is found in developing

(c) The Author(s). 2019 Open Access This article is distributed under the terms of the Creative Commons Attribution 4.0 International License (http://creativecommons.org/licenses/by/4.0/), which permits unrestricted use, distribution, and reproduction in any medium, provided you give appropriate credit to the original author(s) and the source, provide a link to the Creative Commons license, and indicate if changes were made. The Creative Commons Public Domain Dedication waiver (http://creativecommons.org/publicdomain/zero/1.0/) applies to the data made available in this article, unless otherwise stated. 
countries and it has been estimated that about 125 million episodes of diarrhea [6,7]. These viruses are transmitted through fecal-oral route, which is known to be contagious from person to person which can happen by person to person contacts [7]. Rotaviruses, as member of Reoviridae family, are icosahedral, nonenveloped, and composed of three concentric layers of proteins with a core consisting of 11-segmented double-stranded RNA that code six structural (VP1-VP4, VP6 and VP7) and six nonstructural (NSP1-NSP6) proteins [8]. Serologically, human rotaviruses are divided into ten serogroups (A-J) and each group is based on genetic properties of major structural protein VP6 [9]. Group A rotaviruses are the major causes of acute diarrhea in infants and young children worldwide. Based on genetic diversity of two outer proteins, VP7 (glycosylated, G-type) and VP4 (protease sensitive, P-type), rotaviruses are classified in multiple serotypes, including 32 different G- and 47 different P genotypes [10]. There are several techniques for the detection of rotavirus in fecal samples. These tests including; virus cultivation, Electron Microscopy (EM), Enzyme-Linked Immunosorbent Assay (ELISA), Latex Agglutination Test (LAT), Polyacrylamide Gel Electrophoresis (PAGE) and Reverse Transcriptase Polymerase Chain Reaction (RT-PCR), which each of the methods have number of advantages and disadvantages [11]. In this regard, we designed this study to determine almost all known rotaviruses of the $G$ and $P$ genotypes in children with acute gastroenteritis in Gorgan, Iran. In this study, we used PAGE and latex agglutination tests for detection of rotavirus in fecal samples. Moreover, we compared the sensitivity and specificity of these tests in detection of rotavirus. To determine the $\mathrm{P}$ and $\mathrm{G}$ genotypes of rotavirus, semi-multiplex RT-PCR technique was carried on in this study. In addition, we reported genotype distribution and epidemiological data for rotavirus infections in samples collected during 1 year (2016-2017) from children with acute gastroenteritis, which admitted to Taleghani hospital, Gorgan, Iran.

\section{Methods}

\section{Definition of diarrhea}

The diarrhea is determined by the occurrence of three or more watery or loose stool daily lasting for at least 3 days [12].

\section{Ethic statement}

This project was approved by the Ethic Committee of Golestan University of Medical Sciences (Ethic code: ir.goums.rec.1396.8), and it has been accomplished under supervision of an infection specialist they have been informed by doctors about this study. In addition, consent was obtained from their mothers.

\section{Fecal sample collection and preparation}

From October 2016 to October 2017, a total of 349 diarrheic stool samples were collected from children (less than 5 years of old) were admitted at Taleghani hospital, Gorgan, Iran, with acute gastroenteritis symptoms including; with or without vomiting, fever, nausea, abdominal pain, and cramp. The fecal specimens were then transported on ice to the department of microbiology at Golestan university of Medical Sciences, Gorgan, Iran. The specimens were diluted with PBS 10\%, and clarified by centrifugation. Clarified supernatants $(1 \mathrm{ml})$ stored at $4-8{ }^{\circ} \mathrm{C}$ for short term storage or were stored at $-70{ }^{\circ} \mathrm{C}$ for the longer term.

\section{Rotavirus antigen detection by latex agglutination test}

Latex agglutination slide test, for screening and detection of VP6 group A rotavirus antigen, was used with the Plasmatec kit (LOT: 218028) following the manufacturer's instructions for stool samples. All the material were brought to room temperature and mixed well before the test. This is a rapid slide test in which latex particles are coated with anti-rotavirus antibodies specific for group A rotavirus antigens present in a fecal supernatant. This test is interpreted able with the naked eye in few min [13].

\section{Polyacrylamide gel electrophoresis (Electropherotyping)} Polyacrylamide gel electrophoresis (PAGE) was performed with slab gels using standard Laemmli's protocol [14]. For complete resolving of viral dsRNA, electrophoresis was performed at room temperature for $16 \mathrm{~h}$ at $20 \mathrm{~mA}$ and $70 \mathrm{~V}$. After electrophoresis, gel was removed from between the glass plates, then fixed and stained simultaneously in a solution containing $5 \%$ ethanol, $1 \%$ nitric acid, and $0.1 \% \mathrm{AgNO}_{3}$ for $5 \mathrm{~min}$; thereafter, the solution was discarded. The gels were rinsed three times with distilled water for $10 \mathrm{~s}$, and then developed with a solution of $1.3 \% \mathrm{NaOH}, 0.5 \% \mathrm{Na}_{2} \mathrm{CO}_{3}$, and $0.4 \% \mathrm{HCOH}$ (30\%) for 1 to 2 min until the appearance of darkstained bands on the yellow background. Development was stopped with a solution containing 5\% ethanol and $1 \%$ nitric acid for $1 \mathrm{~min}$, and the stopping solution was then discarded. Resulting migration patterns can then be visualized by staining the gel with silver nitrate $[15,16]$.

\section{Viral RNA extraction and reverse transcription}

To extract viral RNA, a standard phenol-chloroform extraction method with RNX-Plus reagent (CinnaGen, Tehran, Iran) was used for stool suspension (prepared in PBS). A $400-\mu \mathrm{l}$ from each fecal suspension was collected for total RNA extraction using RNX-Plus reagent (CinnaGen kit, Iran) according to the manufacturer's protocol. RNA extracts were stored at $-70^{\circ} \mathrm{C}$ for more analysis including; polyacrylamide gel electrophoresis (PAGE), reverse 
Table 1 VP7 and VP4 consensus and type-specific primers

\begin{tabular}{|c|c|c|c|c|}
\hline Primer & Type & Sequence $\left(5^{\prime} \rightarrow 3^{\prime}\right)$ & Position & PCR product (bp \\
\hline \multicolumn{5}{|l|}{ Universal primer } \\
\hline VP7 con1 Forward & & ATGTATGGTATTGAATATACCAC & $51-71$ & 1014 \\
\hline VP7 con2 Reverse & & GGTCACATCATACAATTCTAATC & $1062-1040$ & \\
\hline VP4 con1 Forward & & TGGCTTCGCTCATTTATAGACA & $2-23$ & 877 \\
\hline VP4con1 Reverse & & ATYTCHGACCAYTTATAHCC & $878-859$ & \\
\hline \multicolumn{5}{|l|}{ G-typing (VP7) } \\
\hline Gcon Reverse & & GGTCACATCATACAATTCT & $1062-1044$ & \\
\hline aBT1 & G1 & CAAGTACTCAAATCAATGATGG & $314-335$ & 749 \\
\hline $\mathrm{aCT} 2$ & G2 & CAATGATATTAACACATTITCTGTG & $411-435$ & 652 \\
\hline Aust & G3 & ACGAACTCAACACGAGARG & $250-269$ & 813 \\
\hline aDT4 & G4 & CGTTTCTGGTGAGGAGTTG & $480-498$ & 58 \\
\hline aAT8 & G8 & GTCACACCATTTGTAAATTCG & $178-198$ & 88 \\
\hline mG9 & G9 & CTTGATGTGACTAYAAATAC & $757-776$ & 305 \\
\hline \multicolumn{5}{|l|}{ P-typing (VP4) } \\
\hline con3 Forward & & TGGCTTCGCTCATTTATAGACA & $11-32$ & \\
\hline $2 \mathrm{~T}-1$ & $\mathrm{P}[4]$ & CTATTGTTAGAGGTTAGAGTC & $474-494$ & 484 \\
\hline $3 \mathrm{~T}-1$ & $P[6]$ & TGTTGATTAGTTGGATTCAA & $259-278$ & 260 \\
\hline $1 \mathrm{~T}-1$ & $\mathrm{P}[8]$ & TCTACTTGGATAACGTGC & $339-356$ & 346 \\
\hline $4 \mathrm{~T}-1$ & $\mathrm{P}[9]$ & TGAGACATGCAATTGGAC & $385-402$ & 392 \\
\hline
\end{tabular}

transcription polymerase chain reaction (RT-PCR). Following the RNA extraction, 6- $\mu$ l extracted dsRNA was converted to cDNA, with a High Capacity cDNA Reverse Transcription Kit (Applied biosystems, USA). Before the reverse transcription reaction, the RNA samples were incubated at $97^{\circ} \mathrm{C}$ for $10 \mathrm{~min}$ with random hexamer primer ( $1 \mu \mathrm{M}$ final concentration). The initial reverse transcription reaction was carried out at $25^{\circ} \mathrm{C}$ for $10 \mathrm{~min}, 37^{\circ} \mathrm{C}$ for 120 min, followed by an inactivation step of $85^{\circ} \mathrm{C}$ for $5 \mathrm{~min}$.

\section{Semi-nested multiplex RT-PCR for G and P genotyping}

Genotyping of positive samples were performed according to the WHO genotyping method. All of the rotavirus positive samples were tested by semi-nested RT-PCR with specific primers for regions of the genes encoding the VP7 (G-type) and VP4 (P-type). The appropriate forward and reverse primers for the identification of VP7 and VP4 genotypes of selected sample are presented in Table 1. First and second amplifications were performed as indicated in Table 2. The PCR products were electrophoresed using 2\% agarose gel, and the G and P genotypes were determined by the sizes of the amplicons .

\section{Statistical analysis}

Data were statistically analyzed by the software SPSS, version 19.0. Differences between the groups according to the variables were analyzed using the chisquare test. $P$ values $\leq 0.05$ were considered statistically significant.

\section{Results}

Characteristics of fecal specimens and demographic data Three hundred forty-nine fecal samples were collected from 214 (61\%) males and 135 (39\%) females with acute

Table $2 \mathrm{G}$ and $\mathrm{P}$ typing PCR programs

\begin{tabular}{|c|c|c|c|c|c|c|c|c|c|c|c|}
\hline & \multicolumn{8}{|l|}{ Denaturation } & \multicolumn{3}{|c|}{ Extension } \\
\hline & \multirow[t]{3}{*}{ Temperature } & \multirow[t]{3}{*}{ Time } & & & & & & & \multicolumn{2}{|c|}{ Temperature } & \multirow[t]{3}{*}{ Time } \\
\hline & & & \multicolumn{2}{|c|}{ Denaturation } & \multicolumn{2}{|c|}{ Annealing } & \multicolumn{2}{|c|}{ Extension } & & & \\
\hline & & & Temp & Time & Temp & $\overline{\text { Time }}$ & Temp & $\overline{\text { Time }}$ & \multicolumn{2}{|c|}{ No. cycles } & \\
\hline G typing 1st round & 94 & 5 & 94 & 1 & 42 & 2 & 72 & 1 & 35 & 72 & 7 \\
\hline 2nd round & 94 & 5 & 94 & 1 & 45 & 2 & 72 & 1 & 15 & 72 & 7 \\
\hline$P$ typing $* 1$ st round & 94 & 5 & 94 & 1 & 52 & 1 & 72 & 1 & 35 & 72 & 7 \\
\hline 2nd round & 94 & 5 & 94 & 1 & 52 & 1 & 72 & 1 & 20 & 72 & 7 \\
\hline
\end{tabular}



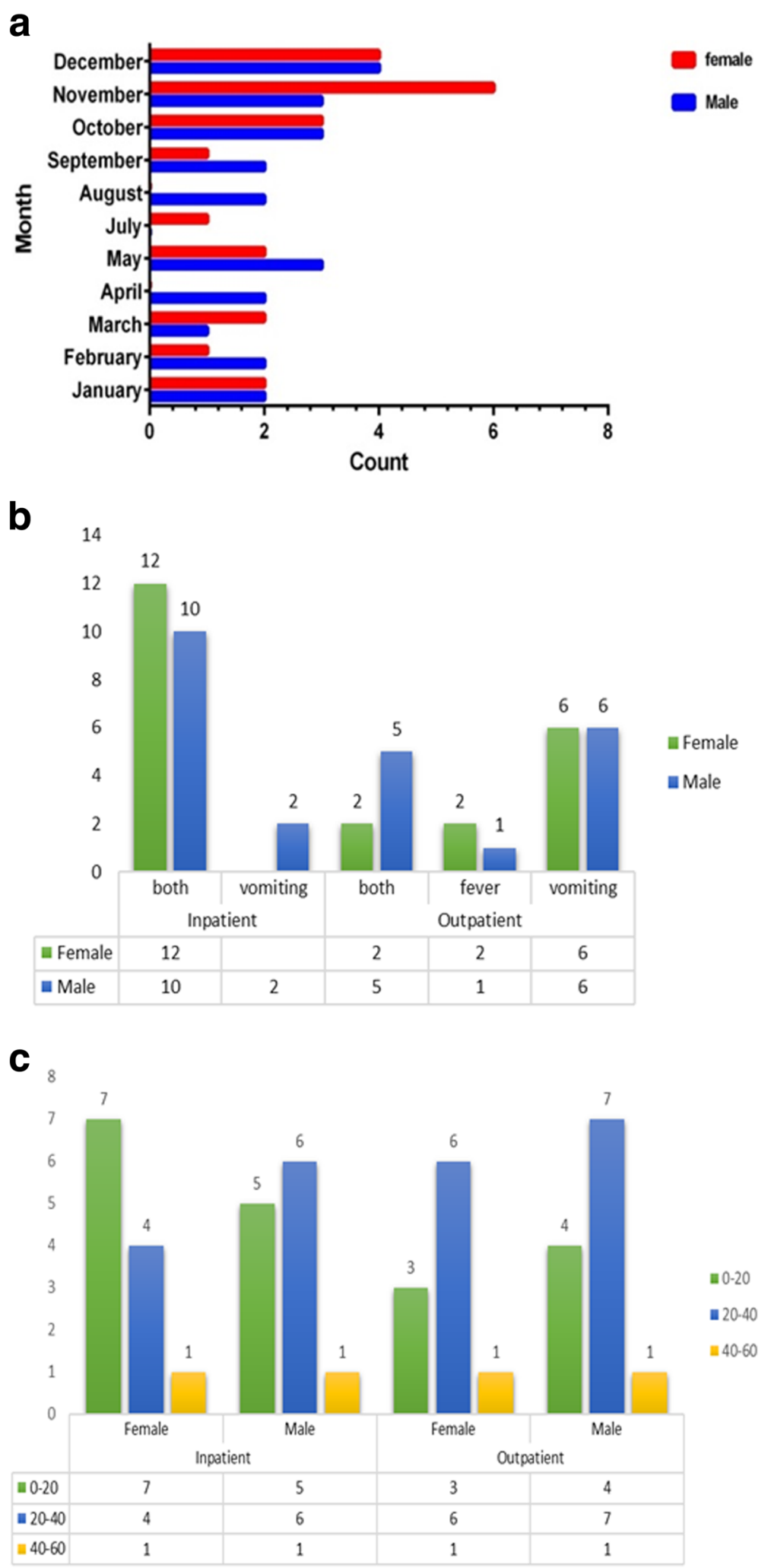

Fig. 1 (See legend on next page.) 
(See figure on previous page.)

Fig. 1 a. Monthly distribution of rotavirus detection in the Northern Iran, from 2016 to 2017. b Distribution of number of vomiting and fever in acute gastrointestinal cases tested positive for rotavirus from 2016 to 2017. c Age distribution of rotavirus detection rate in Northern Iran, from 2016 to 2017. Age ranges for each age group are indicated in color bars as follows: 0-20 months (Green bars), 20-40 months (Blue bars), 0-20 months (Yellow bars)

gastroenteritis during October 2016 to October 2017. All the children with gastroenteritis were aged 0 to 60 months. Rotavirus was detected more in boys than $(52.2 \%, 24 / 46)$ in girls $(47.8 \%, 22 / 46)$. The age group analysis of rotavirus-positive cases revealed that the highest infection rate was among children between 20 and 40 months, with a mean age of $13.40 \pm 11.01$ months, while those within the age ranges of $0-2$ and 48-59 months were the least affected, because no rotavirus infection was detected. The study of clinical pictures in positive cases showed that most children with infection had diarrhea (96.25\%), vomiting (93.4\%) and fever (69.5\%).Rotavirus was detected throughout the year but relative frequency of rotavirus gastroenteritis was the highest in autumn. The seasonal distribution of rotavirus infection was as follow: $21.7 \%$ in spring, $6.5 \%$ in summer, $39.1 \%$ in autumn, and $32.6 \%$ in winter. A significant relationship was also found between rotavirus infection and seasonal distribution $(P<0.05)$ and the highest rate of detection of rotavirus gastroenteritis was found in November (19\%) and the lowest in the months Jun and July, in which no infection was detected $(P=$ 0.04) (Fig. 1A-C).

\section{Polyacrylamide gel electrophoresis analysis}

In this study, initial screening for presence of group A human rotavirus genome in 345 fecal samples was performed by direct dsRNA extraction of samples with RNX-Plus reagent and RNA-PAGE analysis following the previously described procedure. Electrophoretic

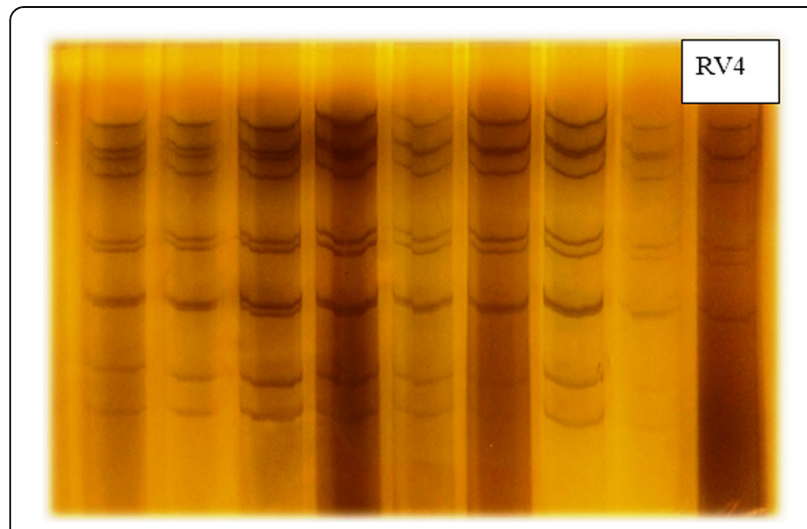

Fig. 2 Electrophoretic migration pattern of RNA from rotavirus strains isolated. RV4 is used as the marker. The viral RNAs were analyzed by RV4 electrophoresis in a 12\% polyacrylamide gel for 16 $\mathrm{h}$ and visualized by silver nitrate migration pattern of dsRNA genome of group A rotavirus (4:2:3:2), was detected in all positive (39/349) fecal samples collected from diarrheic children. The results obtained by followed by PAGE analysis of the extract are shown in Fig. 2.

\section{Serologic identification of rotavirus}

In the present study, Latex slide agglutination test was carried out on 349 stool samples were collected from children aged $<5$-years-old patients, suffering with diarrhea. In the procedure, a sample was considered positive for rotavirus when agglutination was observed within two minutes reaction, as indicated in Fig. 3. Latex slide agglutination test was positive in 38 of 349 (10.88\%) stool specimens for the presence of group A rotavirus antigen.

\section{Identification of $\mathrm{G}$ and $\mathrm{P}$ genotypes in rotavirus-positive specimens}

According to RT-PCR analysis, a total of 46 samples were positive for rotavirus. Twenty-eight (60.8\%) fecal specimens contained only one rotavirus strain and $14(30.4 \%)$ were mixed rotavirus infections. Overall, during the study, $57.82 \%$ of strains identified were genotype G1, $18.70 \%$ G2, $4.69 \%$ G3, 3.13\% G4, 3.13\%G8, 6.26\% G9 and 6.26\% non-typeable $\mathrm{G}$, Of these rotavirus strains, 46 were characterized as P [8] (97.80\%) and p [4] (2.20\%).Our analysis of the G and P

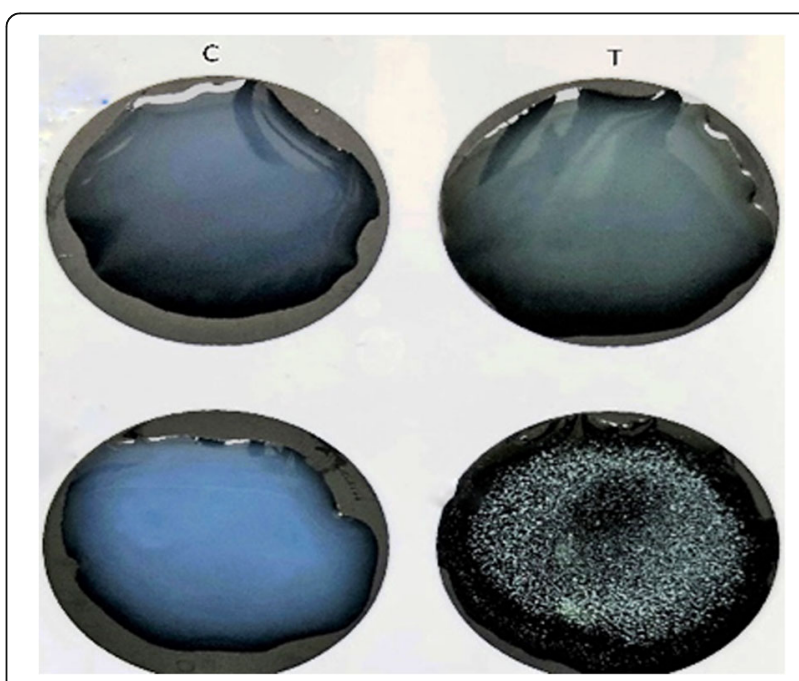

Fig. $\mathbf{3}$ Latex agglutination test of fecal supernatant in patients with diarrhea. Agglutination of latex particles were occurred, when group A rotavirus antigens present in fecal sample and this agglutination interpreted with the naked eye in few min 

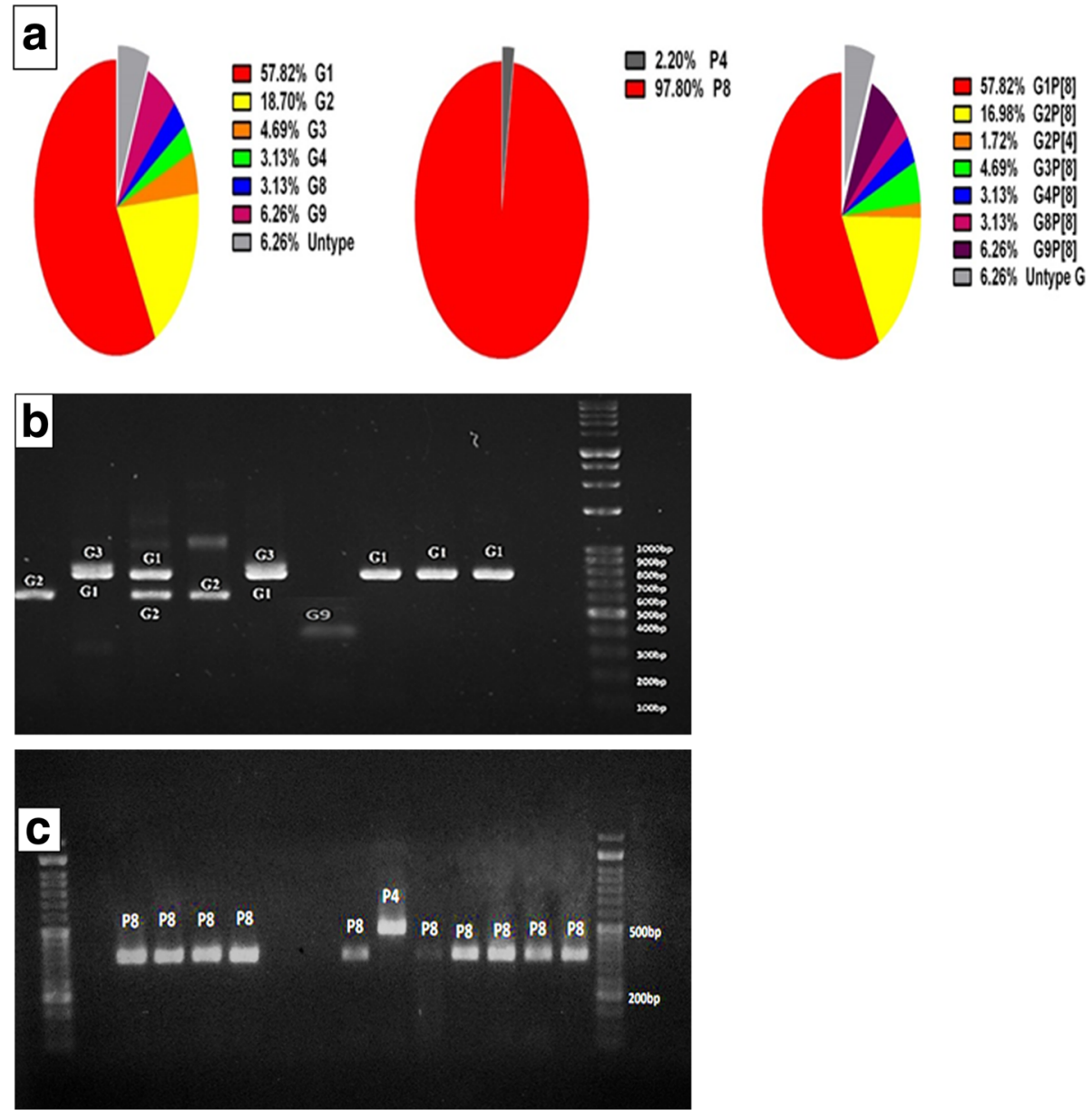

Fig. 4 Distribution of G and P types found in 46 rotavirus-positive fecal samples in Northern Iran from 2016 to 2017. Figure 4 a Pie chart of G Genotypes, P Genotypes and combination Genotypes found in the fecal samples of acute gastrointestinal patients (denoted by their percentages). b Representative agarose gel electrophoresis of PCR products of $G$ typing. $\mathbf{c}$ Representative agarose gel electrophoresis of PCR products of semi-multiplex $P$ typing

genotypes of strains from all 46 rotavirus-infected children revealed: 4/46(6.26\%) G type strains were found to be nontypeable. The predominant single $\mathrm{G} / \mathrm{P}$ combination was G1P [8] (57.82\%), followed by, G2P [8] (16.98\%), G2P [4] (1.72\%), G3P [8] (4.69\%), G4P [8] (3.13\%) G8P [8] (3.13\%), G9P [8] (6.26\%) and four cases of non-typeable G (6.26\%). Rotavirus was detected in 39 specimens (11.17\%) by PAGE, in 38 specimens $(10.88 \%)$ by LAT. Both tests were $100 \%$ specific; however, the LAT was $82.61 \%$ sensitive compared to the PAGE, which was $84.78 \%$ sensitive. The distribution of human rotavirus G/P combinations is shown in Fig. 4a. Amplicon sizes of $\mathrm{P}$ and $\mathrm{G}$ genotypes are presented in Fig. $4 \mathrm{~b}$ and $\mathrm{c}$, respectively.
Comparison of commercially latex slide agglutination test with PAGE analysis

Fecal samples from 349 children with diarrhea were tested for Rotavirus by the Rotatest latex slide agglutination test, the PAGE. Rotavirus was detected in 39 specimens $(11.17 \%)$ by PAGE, in 38 specimens $(10.88 \%)$ by LAT. The concordance of results among the two tests is shown in Table 3. Both tests were $100 \%$ specific; however, the LAT was $82.61 \%$ sensitive compared to the PAGE, which was $84.78 \%$ sensitive. These results indicate that the LAT kit used for rotavirus detection on feces performed properly, with a great simplicity and speed.

Table 3 Comparison of outcomes from two testing methods for human rotavirus in total fecal samples

\begin{tabular}{lllllllll}
\hline Test & True positive & False positive & True negative & False negative & Sensitivity & Specificity & Positive predictive value & Negative predictive value \\
\hline LAT & 38 & 2 & 301 & 8 & $82.61 \%$ & $99.34 \%$ & $95 \%$ & $97.41 \%$ \\
PAGE & 39 & 0 & 303 & 7 & $84.78 \%$ & $100 \%$ & $100 \%$ & $97.74 \%$ \\
\hline
\end{tabular}




\section{Discussion}

Rotavirus is the most common cause of non-bacterial and severe gastroenteritis in young children in different regions of world, including developed and developing countries. This pathogen is responsible for more than 1.5 million hospitalizations and more than 128,000 deaths in children younger than 5 years of age worldwide [17]. The current study provides beneficial data in the context of epidemiology of rotavirus infections in children and infants with acute gastroenteritis, northern Iran, Gorgan.

The prevalence of rotavirus is dependent to several factors, including season of sampling, demographic (e.g. age, sex) and ethnic factors, and the specificity and sensitivity of the diagnostic methods $[4,18]$. In a recent study, Monavari et al., reported a range of 6.4 to $79.3 \%$ of rotavirus infection, with the mean prevalence of $39.9 \%$ among the Iranian children [19]. According to the recent epidemiologic studies, increased worldwide prevalence of rotavirus among children aged less than 5 years in 1986-1999 was 20\%, in 1990-2004 was 29\%, and in 2001-2008 was $40 \%$ [20]. Similarly, up to $42.77 \%$ of rotavirus prevalence was reported in the Eastern Mediterranean region in 2010-2015 [21]. The rate of rotavirus in the present study was $13 \%$. This widespread variability may be explained by above-mentioned variables.

Regarding this fact that rotavirus is considered as an etiologic agent of severe gastroenteritis in young children, screening and identification of patients in developing countries seems to be necessary. There are three categories of diagnostic methods for detection and typing of rotavirus from fecal specimens as follow: 1) Electron microscopy (EM) and nucleic acid detection by poly acrylamide gel (RNA-PAGE), 2) Antigen detection tests, including enzyme immunoassay (EIA), latex agglutination tests (LAT), and 3) nucleic acid amplification assay (RT-PCR) [11, 22]. EM is highly specific and sensitive for detection of rotavirus. However, it is a timeconsuming and costly technique and requires a highly trained technician. In addition, EM cannot distinguish different groups of rotaviruses [11,22]. Because of the large quantities of rotavirus presented in stool samples, RNA-PAGE can be used for detection and typing of human rotaviruses. Like EM method, this method is timeconsuming and requires a trained technologist. However, this method is powered by several advantages, including good sensitivity, detection of small amounts of virus, lack of ambiguity in the results and distinguishing different rotaviruses [11, 22]. Serological tests, such as ELISA and LAT are the commonly methods used for rotavirus diagnosis based on antigen detection in stool material. The LAT is a simple, rapid, sensitive and specific for routine performance in laboratories [23, 24].
In our study, 11.17 and $10.88 \%$ of specimens were positive for group A human rotavirus by PAGE and LAT, respectively. LAT has been shown as a method with good sensitivity and specificity in previous studies. One study conducted by Al-Yousif et al, the sensitivity and specificity of LAT in compared with ELISA were obtained 100 and 96.3\%, respectively [23]. In second study, Haikala et al, reported that LAT is more sensitive than EM and ELISA assays [25]. Similarly, the LAT assay in the current study showed enough sensitivity and specificity. According to the fact that this method is easy to perform in short time and does not need expensive equipment, the LAT could be recommended for routine performance in laboratories.

The results of $P$ and $G$ typing in this study revealed that genotype G1P [8] was dominant with the prevalence of $57.82 \%$, followed by the genotypes G2P [8] (16.98\%), G2P [4] (1.72\%) G3P [8] (4.69\%), G4P [8] (3/13\%), G8P [8] (3.13\%) and G9P [8] (6.26\%) and non-typeable G (6.26\%). The G1P [8], G2P [4], G3P [8], G4P [8], G9P [8], and G9P [6], have been reported as the most dominant genotypes in the USA and most European countries [21]. In a recent study, Azaran et al, reported the prevalence rate of $28.13 \%$ for genotype G9P [8] in patient with gasteroentrititis during 2015 to 2016 [26]. In contrast, G1P [8] was found as dominant genotype (57.82\%) among the patient studied in the current study. In agreement with our study, previous studies conducted in Iran found similar findings [21, 27], Modaress et al, found G1P [8] as dominant genotype with a prevalence rate of $53.4 \%$ [28].

Here, it was found that there was no significant correlation between the rotavirus genotypes and clinical features, a figure that is inconsistent with by previous studies [13, 21, 29]. Rotavirus was shown in tropical climates throughout the year and also, its seasonal trends are less well defined. In this study, we found a significant correlation between the rotavirus and season, in agreement with other investigations [18]. Rotavirus-related gastroenteritis in our enrolled patient was occurred in autumn, with peaks in November and December.

Until recently, more than 60 countries have been performed vaccination of children against rotavirus and some of these countries demonstrated decreases of $22-50 \%$ in diarrhea mortality among children $<5$ years of age [29]. One of the most important challenges for future rotavirus vaccine is absence of epidemiological studies and sufficient information about geographical distribution of different human rotavirus strains. Furthermore, it has demonstrated the importance and need for production of polyvalent rotavirus vaccine against circulating new rotavirus strains as suggested by WHO, which will help measures to control rotavirus epidemics in the future. 


\section{Conclusion}

This study emphasizes to conduct a large-scale study to characterize rotavirus strains and to determine their trend over time among Iranian children with acute gastroenteritis using valid and rapid laboratory technique. To design new effective vaccines for infant's aged under 5-years-old, such studies appear to be necessary.

\section{Abbreviations}

dsRNA: double stranded RNA; ElA: Enzyme Immunoassay; ELISA: EnzymeLinked Immunosorbent Assay; EM: Electron microscopy; LAT: Latex Agglutination Tests; PAGE: Polyacrylamide Gel Electrophoresis; RTPCR: Reverse Transcriptase-Polymerase Chain Reaction; RV: Rotavirus; WHO: World Health Organization

\section{Acknowledgments}

The authors would like to thank the Taleghani hospital staff as well as the laboratory staff and the Department of Microbiology, Golestan University of Medical Sciences, Gorgan, Iran, for the technical support.

\section{Authors' contributions}

$\mathrm{HR}$, AT and AM designed the study. NL, MM and $\mathrm{MH}$ collected and analyzed samples. NL, NJ and SK interpreted the data and drafted the manuscript. AA, AJT contributed to analyzing the results and reviewing the article. HR was involved in the interpretation of results and reviewing the article. All authors critically revised the manuscript and approved the final version.

\section{Funding}

This study was granted by the research deputy of Golestan University of Medical Sciences for (Grant number, 960628138). This project was extracted from the MSc thesis with ethic code IR.GUOMS.REC.1396.8.

\section{Availability of data and materials}

The datasets used and/or analyzed during the current study are available from the corresponding author on reasonable request.

\section{Ethics approval and consent to participate}

This project was approved by the Ethic Committee of Golestan University of Medical Sciences (Ethic code: ir.goums.rec.1396.8). All subjects were informed of the purpose and experimental of procedures of the study. In addition, written consent was obtained from their mothers.

\section{Consent for publication}

Not applicable.

\section{Competing interests}

The authors report no conflict of interest in this work.

\section{Author details}

${ }^{1}$ Laboratory Sciences Research Center, Golestan University of Medical Sciences, Gorgan, Iran. ²Department of Microbiology, Faculty of Medicine, Golestan University of Medical Sciences, Gorgan, Iran. ${ }^{3}$ Department of Microbiology, Faculty of Medicine, Hamadan University of Medical Sciences, Hamadan, Iran. ${ }^{4}$ Hepatitis Research Center, Lorestan University of Medical Sciences, Khorramabad, Iran. ${ }^{5}$ Department of Virology, Faculty of Medicine, Lorestan University of Medical Sciences, Khorramabad, Iran.

Received: 15 April 2019 Accepted: 17 June 2019

Published online: 20 June 2019

\section{References}

1. Troeger C, Blacker BF, Khalil IA, Rao PC, Cao S, Zimsen SR, Albertson SB, Stanaway JD, Deshpande A, Abebe Z. Estimates of the global, regional, and national morbidity, mortality, and aetiologies of diarrhoea in 195 countries: a systematic analysis for the global burden of disease study 2016. Lancet Infect Dis. 2018;18(11):1211-28.

2. Chow CM, Leung AK, Hon KL. Acute gastroenteritis: from guidelines to real life. Clinic Exp Gastroenterol. 2010;3:97.
3. Santos N, Hoshino Y. Global distribution of rotavirus serotypes/genotypes and its implication for the development and implementation of an effective rotavirus vaccine. Rev Med Virol. 2005;15(1):29-56.

4. Fletcher SM, McLaws M-L, Ellis JT. Prevalence of gastrointestinal pathogens in developed and developing countries: systematic review and metaanalysis. J Public Health Res. 2013;2(1):42.

5. Cukor G, Blacklow NR. Human viral gastroenteritis. Microbiol Rev. 1984;48(2):157.

6. Desselberger U, Iturriza-Gómara M, Gray JJ. Rotavirus epidemiology and surveillance. In: Gastroenteritis Viruses: Novartis Foundation Symposium 238: 2001: Wiley online library; 2001. p. 125-52.

7. Parashar UD, Gibson CJ, Bresee JS, Glass RI. Rotavirus and severe childhood diarrhea. Emerg Infect Dis. 2006;12(2):304

8. Estes MK, Cohen J. Rotavirus gene structure and function. Microbiol Rev. 1989;53(4):410-49.

9. Greenberg H, McAuliffe V, Valdesuso J, Wyatt R, Flores J, Kalica A, Hoshino Y, Singh N. Serological analysis of the subgroup protein of rotavirus, using monoclonal antibodies. Infect Immun. 1983:39(1):91-9.

10. Estes MK, Palmer EL, Obijeski JF: Rotaviruses: a review. Current Topics Microbiol Immunol. edn.: Springer; 1983: 123-184.

11. Organization $\mathbf{W H}$ : manual of rotavirus detection and characterization methods. 2009.

12. Ruiz-Palacios GM, Pérez-Schael I, Velázquez FR, Abate H, Breuer T, Clemens SC, Cheuvart B, Espinoza F, Gillard P, Innis BL. Safety and efficacy of an attenuated vaccine against severe rotavirus gastroenteritis. New England $J$ Med. 2006;354(1):11-22.

13. Sambourg M, Goudeau A, Courant C, Pinon G, Denis F. Direct appraisal of latex agglutination testing, a convenient alternative to enzyme immunoassay for the detection of rotavirus in childhood gastroenteritis, by comparison of two enzyme immunoassays and two latex tests. J Clinic Microbiol. 1985;21(4):622-5.

14. He F. Laemmli-sds-page. Bio-protocolBio101. 2011:e80

15. Schägger H. Tricine-sds-page. Nat Protoc. 2006;1(1):16.

16. Beidler $\mathrm{L}$, Hilliard PR, Rill RL. Ultrasensitive staining of nucleic acids with silver. Anal Biochem. 1982;126(2):374-80.

17. Parashar UD, Hummelman EG, Bresee JS, Miller MA, Glass RI. Global illness and deaths caused by rotavirus disease in children. Emerg Infect Dis. 2003; 9(5):565.

18. Patel MM, Pitzer V, Alonso WJ, Vera D, Lopman B, Tate J, Viboud C, Parashar UD. Global seasonality of rotavirus disease. The Pediatr Infect Dis. 2013;32(4):e134.

19. Monavari SHR, Hadifar S, Mostafaei S, Miri A, Keshavarz M, Babaei F, Moghoofei M. Epidemiology of rotavirus in the Iranian children: a systematic review and meta-analysis. J Global Infect Dis. 2017;9(2):66.

20. Tate JE, Burton AH, Boschi-Pinto C, Steele AD, Duque J, Parashar UD. 2008 estimate of worldwide rotavirus-associated mortality in children younger than 5 years before the introduction of universal rotavirus vaccination programmes: a systematic review and meta-analysis. The Lancet Infect Dis. 2012;12(2):136-41.

21. Jalilvand S, Roohvand F, Arashkia A, Shoja Z. Update on epidemiology and circulating genotypes of rotavirus in Iranian children with severe diarrhea: 1986-2015. Intern J Travel Med Global Health. 2018;6(1):7-10.

22. Soltan MA, Tsai Y-L, Lee P-YA, Tsai C-F, Chang H-FG, Wang H-TT, Wilkes RP. Comparison of electron microscopy, ELISA, real time RT-PCR and insulated isothermal RT-PCR for the detection of rotavirus group a (RVA) in feces of different animal species. J Virol Methods. 2016;235:99-104.

23. Al-Yousif $Y$, Anderson J, Chard-Bergstrom C, Bustamante A, Muenzenberger M, Austin K, Kapil S. Evaluation of a latex agglutination kit (Virogen Rotatest) for detection of bovine rotavirus in fecal samples. Clinic Diag lab immun. 2001;8(3):496-8.

24. AL-Khafaji Y, AL-Jiboury HJ. Detection of rotavirus in diarrhea stool samples of children with acute gastroenteritis in Babylon governorate, Iraq. Intern Res J Microbiol. 2013:4(3):84-8.

25. Ferreira $T L$, Becho MC, Bernardo AR, Chaves TCB, Ribeiro RS, JSd L, Fialho AM, Leite JPG, Mazur C, Danelli MGM. Performance of a latex agglutination test in the diagnosis of acute gastroenteritis by rotavirus. Brazilian 」 Microbiol. 2006;37(4):587-9.

26. Azaran A, Makvandi M, Teimoori A, Ebrahimi S, Heydari F, Nikfar R. Distribution of rotavirus genotypes circulating in Ahvaz, Iran in 2016. Iran Biomed J. 2018:22(2):107.

27. Enweronu-Laryea CC, Sagoe KW, Damanka S, Lartey B, Armah GE. Rotavirus genotypes associated with childhood severe acute diarrhoea in southern Ghana: a cross-sectional study. Virol J. 2013;10(1):287. 
28. Rahbarimanesh AA, Sayari AA. Human rotavirus genotypes detection among hospitalized children, a study in Tehran, Iran. Arch Iran Med. 2011;14(1):39.

29. Tate JE, Burton AH, Boschi-Pinto C, Parashar UD, WHOCGRS N, Agocs M, Serhan F, de Oliveira L, Mwenda JM, Mihigo R. Global, regional, and national estimates of rotavirus mortality in children $<5$ years of age, 2000-2013. Clinic Infect Dis. 2016;62(suppl_2):S96-S105.

\section{Publisher's Note}

Springer Nature remains neutral with regard to jurisdictional claims in published maps and institutional affiliations.

Ready to submit your research? Choose BMC and benefit from:

- fast, convenient online submission

- thorough peer review by experienced researchers in your field

- rapid publication on acceptance

- support for research data, including large and complex data types

- gold Open Access which fosters wider collaboration and increased citations

- maximum visibility for your research: over $100 \mathrm{M}$ website views per year

At BMC, research is always in progress.

Learn more biomedcentral.com/submissions 